American Journal of Agricultural and Biological Sciences 6 (2): 249-255, 2011

ISSN 1557-4989

(C) 2011 Science Publications

\title{
Dietary Inclusion of Probiotics, Prebiotics and Synbiotic and Evaluating Performance of Laying Hens
}

\author{
${ }^{1}$ Mohammad Zarei, ${ }^{2}$ Mohammad Ehsani and ${ }^{3}$ Mehran Torki \\ ${ }^{1}$ Member of Young Researchers Club of I.A.U. Aligodarz Branch, Iran \\ ${ }^{2}$ Dapratment of Animal Science, Agriculture Faculty, Razi University, \\ Imam Avenue, Kermanshah, Iran
}

\begin{abstract}
Problem Statement: This study was conduct to compare effects of various commercial feed additives on performance of laying hens. Approach: To evaluate effects of dietary inclusion of feed additives (Yeasturer, A-Max, Thepax, Fermacto and Biomin) on performance of laying hens, 216 Lohmann LSL-Lite hens were divided in 36 cages $(n=6)$. Approach Hens in 6 cages (replicates) were assigned to feed on one of the 6 iso-caloric and iso-nitrogenous experimental diets (ME $=2720 \mathrm{Kcal}$ $\mathrm{Kg}^{-1}$ and $\left.\mathrm{CP}=145 \mathrm{~g} \mathrm{~kg}^{-1}\right)$ including control and diets with $0.5 \mathrm{~g} \mathrm{~kg}^{-1}$ of feed additives. Collected data of Feed Intake (FI), Egg Production (EP), Egg Weight (EW), Egg Mass (EM) and calculated Feed Conversion Ratio (FCR) during 6-week trial period was analyzed based on completely randomized design using GLM procedure of SAS. Results and Conclusions: Dietary additive inclusion significantly affected on EW on 1-3 and 3-6 weeks. Feed additive did not have significant effect on EP, FCR, FI and EM. There was no significant difference in EP, EM, FI and FCR among the experimental groups. Hens received Yeasturer or A-Max showed improved EW compared to hens fed the control diet during weeks 1-3. Hens fed diets included additives showed improved egg shell weight and thickness compared to hens fed the control diet. There was no significant effect of dietary treatment on blood levels of cholesterol, TG and HDL. Adding Thepax or Biomin to diet significantly reduced blood levels of LDL compared to hens fed the other experimental diets. There was no significant effect of dietary treatment on diacritical counts of white blood cells. Recommendations: According to the results of the present study, probiotic Yesture and A-Max can be included in laying hens diets to improve EM. In addition, the commercial feed additives (Yeasturer, A-Max, Thepax, Fermacto and Biomin) used in this study had beneficial effects on egg shell quality characteristics in terms of shell weight and thickness and to decrease egg abnormalities due to poor shell, these feed additives could be recommendable.
\end{abstract}

Key words: Probiotics, laying hens, eggs quality, Feed Intake (FI), Egg Production (EP), Egg Weight (EW), Egg Mass (EM) Feed Conversion Ratio (FCR), intestinal microflora, diacritical counts, white blood cells, significant effect, experimental diets

\section{INTRODUCTION}

Gibson and Roberfroid (1995) first defined prebiotics as 'non-digestible food ingredients that beneficially affect the host by selectively stimulating the growth and/or activity of one, or a limited number of, bacteria in the colon'. Prebiotics must be indigestible to the animal host while remaining available to the probiotic bacteria. Futhermore, a prebiotic should be included at low quantities in the animal diet so that there is negligible effect on the inclusion of other necessary dietary ingredients (Roberfroid, 2001). A probiotic is a culture of a single bacteria strain, or mixture of different strains, that can be fed to animals to improve some aspect of their health. Probiotics are also referred to as direct fed microbial (La Ragione et al, 2001). Numerous studies in humans and animals have been conducted to assess the ability of probiotics to change the type and number of the microflora in the digestive tract (Gibson and Fuller, 2000). Some investigations on probiotics with laying hens indicated positive responses to dietary supplementation (Li et al., 2006; Kurtoglu et al., 2004). In addition, Gallazzi et al. (2008) and observed significant improvements in egg

Corresponding Author: Mehran Torki, Department of Animal Science, Agriculture Faculty, Razi University, Kermanshah, Iran, 
production in layers receiving probiotics. Prebiotics are nondigestible carbohydrates; many of these carbohydrates are short chains of monosaccharides, called oligosaccharides. Some oligosaccharides are thought to enhance the growth of beneficial organisms in the gut and others are thought to function as competitive attachment sites for pathogenic bacteria. Two of the most commonly studied prebiotic oligosaccharides are Fructo Oligo Saccharides (FOS) and Mannan Oligo Saccharides (MOS). Xu et al. (2003) studied the effect of FOS, at 4 levels of dietary inclusion, on growth performance and intestinal microflora in broilers. They reported that the diets containing $0.4 \%$ FOS resulted in significant improvements in average daily gain and feed efficiency compared with those fed the control

The objective of this study was to compare effects of diet addition of probiotics (Thepax and Yeasturer), prebiotics (Fermacto and A-Max) and synbiotic (Biomin) on performance of laying hens, egg quality characteristics, biochemical parameters of serum and diacritical counts of white blood cells.

\section{MATERIALS AND METHODS}

A total number of 216 Lohmann LSL-Lite hens were divided in 36 cages $(n=6)$ with almost equal distribution of average body weight and egg production among cages. Hens in 6 cages (replicates) were assigned to feed on one the 6 experimental diets. Based on a completely randomized design arrangement of treatments, 6 iso-caloric and iso-nitrogenous diets $(\mathrm{ME}=$ $2720 \mathrm{Kcal} \mathrm{Kg}^{-1}$ and $\mathrm{CP}=145 \mathrm{~g} \mathrm{~kg}^{-1}$ ) consisting control (with no additive) and 5 other diets with additives (Yeasturer (Y), A-Max (AM), Thepax (T), Fermacto (F) and Biomin (B) were formulated (Table 1). Characterizations of the feed additives used in the present experiment were mentioned below.

Yeasturer®, The commercial name of Yeasturer is composed of live yeast cultures selected from three strains Saccharomyces cerevisisiae $\left(1 \times 10^{11}\right.$ cell) in combination with probiotic bacteria (Lactobacillus acidophilus and L. casei $5 \times 10^{9}$ cfu, Sterptococcus faecium $5 \times 10^{9} \mathrm{cfu}$ and Bacillus subtilis $\left.1 \times 10^{10} \mathrm{cfu}\right)$. A$\operatorname{Max}{ }^{\circledR}$, A-Max is Saccharomyces cerevisiae $\left(1 \times 10^{11}\right.$ cell) yeast grown media of sucrose cane and molasses and processed grain by-product. Thepax ${ }^{\circledR}$ is a commercial product containing yeast cells of Saccharomyces cerevisiae a commercial product diet. In piglets fed prebiotics, probiotics or synbiotics (combinations of probiotics and prebiotics) the population of bifidobacteria in the ileum increased and prebiotics and synbiotics increased their body weight gain (Shim et al., 2005). Furthermore, evidence suggests that synbiotics are more effective than are either probiotics or prebiotics alone and that a mixture of probiotic strains may be more effective than the individual strains (Timmerman et al., 2004). Supplementation of a diet with a mixture powder of garlic and thyme may assist in improving performance of laying hens and egg quality traits (Ghasemi et al., 2010). Supplementing corn-soybean or corn-soybeanguar meal diets by $\beta$-mannanase would have beneficial effects on performance of hens especially in terms of FCR and EP (Ehsani and Torki, 2010).

containing yeast cells of Saccharomyces cerevisiae Var. ellipsoideus. Fermacto ${ }^{\circledR}$ is the commercially available fermentation product of Aspergillus orizae referred to as Aspergillus meal with no live cells or spores. Biomin ${ }^{\circledR}$ is a symbiotic with inulin $(40 \%)$ and probiotic strain Enterococcus faecium. The colony forming unit per gram $(\mathrm{cfu} / \mathrm{g})$ of synbiotic was enumerate $5 \times 10^{9}$.

Collected data of Feed Intake (FI), Egg Production (EP), Egg Mass (EM) and calculated Feed Conversion Ratio (FCR) during 6-week trial period was analyzed based on completely randomized design using GLM procedure of SAS.

Table 1: Composition of the experimental diets

\begin{tabular}{lll} 
& Experimental diets & \\
& - Control & Additives \\
Feed ingredients & $\mathrm{g} / 100 \mathrm{~g}$ & 68.67 \\
\hline Corn & 68.67 & 3.000 \\
Fish meal & 3.000 & 15.16 \\
Soybean meal & 15.16 & 1.250 \\
Dicalcium phosphate & 1.250 & 8.480 \\
Limestone & 8.480 & 0.250 \\
Common salt & 0.250 & 2.520 \\
Sand & 2.580 & 0.050 \\
Additives & & 0.500 \\
Vit. \& Min. Premix & & 0.110 \\
DL-Methionine & 0.500 & 27200 \\
Calculated analyses & 0.110 & 14.500 \\
ME (Kcal/kg) & & \\
Crude protein $(\%)$ & 27200 &
\end{tabular}

${ }^{1}$ Yeasture, A-Max, Thepax, Fermacto and Biomin, ${ }^{2}$ The vitamin and mineral premix provide the following quantities,per kilogram of diet: vitamin A, 10,000 IU (all-trans-retinal); cholecalciferol, 2,000 IU; vitamin E, $20 \mathrm{IU}$ ( $\alpha$-tocopheryl); vitamin $\mathrm{K} 3,3.0 \mathrm{mg}$; riboflavin, 18.0 $\mathrm{mg}$; niacin, $50 \mathrm{mg}$; D-calcium pantothenic acid, $24 \mathrm{mg}$; choline chloride, $450 \mathrm{mg}$; vitamin $\mathrm{B} 12,0.02 \mathrm{mg}$; folic acid, $3.0 \mathrm{mg}$; manganese, $110 \mathrm{mg}$; zinc, $100 \mathrm{mg}$; iron, $60 \mathrm{mg}$; copper, $10 \mathrm{mg}$; iodine, $100 \mathrm{mg}$; selenium, $0.2 \mathrm{mg}$; and antioxidant, $250 \mathrm{mg}$ 250 
Am. J. Agri. \& Biol. Sci., 6 (2): 6 (2): 249-255, 2011

\section{RESULTS}

Effects of probiotics, prebiotics and/or synbiotic on EP, FI, FCR, Egg Weight (EW) and EM during experimental period ( 6 weeks) are presented in Table 26 , respectively. There was no significant difference in EP, EM, FI and FCR among the experimental groups. Diet inclusion of probiotics significantly affected on EW (weeks 1-3 and 3-6). Hens received Yeasturer or A-Max showed improved EW compared to hens fed the control diet during weeks 1-3. The effects of dietary treatment on the measured egg quality characteristics were shown in Table 7. Among the egg quality traits, only egg shell weight and shell thickness were significantly affected by dietary additive. Hens fed diets included additives showed improved egg shell weight and thickness compared to hens fed the control diet; however, regarding to egg shell weight the difference between eggs of hens fed Fermacto-included diet and control was not significant $(\mathrm{P}>0.05)$. Effects of adding probiotics, prebiotics and/or synbiotic on blood biochemical parameters (cholesterol, TG, LDL and HDL) are presented in Table 8. There was no significant effect of dietary treatment on blood levels of cholesterol, TG and HDL. There was no significant effect of dietary treatment on diacritical counts of white blood cells (Table 9).

\section{DISCUSSION}

In this study, EP, EM, FI and FCR were not significantly affected by dietary additive. This is in support with results obtained by Mutus et al. (2006) and Kalavathy et al. (2009) who reported that inclusion of probiotic had no significant effect on EP and EM. But Yoruk et al. (2004) and Panda et al. (2003) reported statistically significant increase of produced egg mass in ISA-Brown and Leghorn laying hens fed diet included probiotic during the whole laying period. Mahdavi et al. (2005) reported that addition of Bioplus 2B in diet of commercial layer hen had no positive effect on FI, EP, EW, EM and FCR. Based on some of studies changing in microbial ecology in layers' intestine might enhance their health and improve feed efficiency by the use of feeding probiotics (Aghaei et al., 2010; Chen et al. 2005). Also Sims et al. (2004) showed that turkeys fed diets with $0.1 \%$ MOS for the first $6 \mathrm{wk}$ of life and then $0.05 \%$ for the remainder of the trial had significantly improved FCR compared with the turkeys in the unsupplemented control group at $12-15 \mathrm{wk}$ of age. The reason of variable effect of biological additives may be confounded by variations in gut flora and environmental conditions (Mahdavi et al., 2005).
The inclusion of desirable microorganisms (probiotics) in the diet allows the rapid development of beneficial bacteria in the digestive tract of the host, improving its performance (Edens, 2003). As a consequence, there is an improvement in the intestinal environment, increasing the efficiency of digestion and nutrient absorption processes (Pelicano et al., 2004), which may explain the improvement in egg weight observed in the present study. The efficiency of probiotics, however, will depend on the quantitative and qualitative characteristics of microorganisms used in the production, making it difficult to conduct comparative studies between different products. Balevi et al. (2001) who fed commercial multi strain probiotic to 40 -weekold layers showed no statistically significant differences in EP and EW compared with the control.

Table 2: Egg production (\%) of hens fed experimental diets

\begin{tabular}{|c|c|c|c|}
\hline \multirow[b]{2}{*}{ Weeks } & \multicolumn{3}{|c|}{ Egg production $(\%)$} \\
\hline & $1-3$ & $3-6$ & $1-6$ \\
\hline \multicolumn{4}{|l|}{ Treatments } \\
\hline Control & 80.42 & 92.06 & 86.24 \\
\hline Yeasture & 76.05 & 88.35 & 82.20 \\
\hline A-Max & 83.86 & 92.32 & 88.09 \\
\hline Thepax & 79.49 & 88.49 & 83.99 \\
\hline Fermacto & 78.43 & 86.50 & 82.47 \\
\hline Biomin & 85.79 & 89.35 & 87.57 \\
\hline$P$ value & 0.154 & 0.555 & 0.208 \\
\hline SEM & 2.708 & 2.535 & 2.060 \\
\hline \multicolumn{4}{|c|}{ SEM = Standard Error of Means } \\
\hline \multicolumn{4}{|c|}{ Table 3: Feed intake $\left(\mathrm{g} \mathrm{hen}^{-1} \mathrm{day}^{-1}\right)$ of hens fed experimental diets } \\
\hline & \multicolumn{3}{|c|}{ Feed intake $\left(\mathrm{g} \mathrm{hen}^{-1}\right.$ day $\left.^{-1}\right)$} \\
\hline Weeks & Wk 1-3 & Wk 3-6 & Wk 1-6 \\
\hline \multicolumn{4}{|l|}{ Treatments } \\
\hline Control & 110.73 & 114.39 & 112.56 \\
\hline Yeasture & 109.21 & 116.14 & 112.67 \\
\hline A-Max & 115.77 & 119.17 & 117.47 \\
\hline Thepax & 109.81 & 114.65 & 112.23 \\
\hline Fermacto & 113.48 & 111.81 & 112.64 \\
\hline Biomin & 115.18 & 117.07 & 116.12 \\
\hline$P$ value & 0.0990 & 0.3030 & 0.2400 \\
\hline SEM & 1.9720 & 2.2430 & 1.8790 \\
\hline
\end{tabular}

SEM= Standard Error of Means

Table 4: Feed conversion ratio ( $\mathrm{g}$ feed: $\mathrm{g}$ egg) of hens fed experimental diets

\begin{tabular}{llll}
\hline & Feed conversion ratio & \\
Weeks & Wk 1-3 & Wk 3-6 & Wk 1-6 \\
\hline Treatments & & & \\
Control & 2.290 & 2.000 & 2.150 \\
Yeasture & 2.310 & 2.070 & 2.190 \\
A-Max & 2.190 & 2.040 & 2.120 \\
Thepax & 2.250 & 2.070 & 2.160 \\
Fermacto & 2.390 & 2.120 & 2.250 \\
Biomin & 2.180 & 2.120 & 2.150 \\
P value & 0.466 & 0.662 & 0.593 \\
SEM & 0.080 & 0.057 & 0.055 \\
\hline SEM Standard & &
\end{tabular}

SEM = Standard Error of Means 
Am. J. Agri. \& Biol. Sci., 6 (2): 6 (2): 249-255, 2011

Table 5: Egg weight ( $\mathrm{g}$ ) of hens fed experimental diets Egg weight $(\mathrm{g})$

\begin{tabular}{llll} 
Weeks & Wk 1-3 & Wk 3-6 & Wk 1-6 \\
\hline Treatments & & & \\
Control & $61.12^{\mathrm{b}}$ & $62.05^{\mathrm{ab}}$ & 61.58 \\
Yeasture & $62.95^{\mathrm{a}}$ & $63.47^{\mathrm{a}}$ & 63.21 \\
A-Max & $63.38^{\mathrm{a}}$ & $63.28^{\mathrm{a}}$ & 63.33 \\
Thepax & $62.56^{\mathrm{ab}}$ & $63.07^{\mathrm{a}}$ & 62.82 \\
Fermacto & $60.97^{\mathrm{b}}$ & $61.17^{\mathrm{b}}$ & 61.07 \\
Biomin & $62.05^{\mathrm{ab}}$ & $62.64^{\mathrm{ab}}$ & 62.35 \\
P value & 0.023 & 0.019 & 0.131 \\
& & & \\
SEM & 0.557 & 0.485 & 0.485
\end{tabular}

a-b: Means within a column with no common superscript differ significantly $(\mathrm{p}<0.05)$, SEM $=$ Standard error of means

Table 6: Egg mass (g) of hens fed experimental diets

\begin{tabular}{llcc}
\hline & \multicolumn{2}{c}{ Egg mass $\left(\mathrm{g} \mathrm{hen}^{-1}\right.$ day $\left.^{-1}\right)$} & \\
Weeks & Wk 1-3 & Wk 3-6 & Wk 1-6 \\
\hline Treatments & & & \\
Control & 49.16 & 57.16 & 53.16 \\
Yeasture & 47.92 & 56.05 & 51.98 \\
A-Max & 53.25 & 58.41 & 55.83 \\
Thepax & 49.66 & 55.80 & 52.73 \\
Biomin & 53.20 & 55.96 & 54.58 \\
P value & 0.088 & 0.410 & 0.124 \\
SEM & 1.694 & 1.769 & 1.391 \\
\hline a-b: Means within a column with no common superscript, differ \\
significantly (p<0.05), SEM = Standard error of means
\end{tabular}

They were stated that the difference between their results and previous works may be related to differences in the ages of the hens. Responses to probiotics and prebiotics supplementation are inconsistent. This led to abundant investigations on possible factors that could influence the responses to these additives. In general these additives have proved most effective under conditions of stress, possibly the presence of un-favorable organisms, extremes in ambient temperature, diseases, crowding and poor management. In commercial layers production one or more of these conditions are invariably present. Further possible causes of variations in response to probiotics, prebiotics and/or synbiotic supplementation in layers could be differences between strains, hybrids, age, plane of nutrition, nutrient composition of the diet, microbial population of gastrointestinal tract, levels of inclusion of probiotics, prebiotics and/or synbiotic in the diet, duration of supplementation or other environmental conditions.

Hens fed diets included additives showed improved egg shell weight and thickness compared to hens fed the control diet. This result agreed with the previous report that egg shell weight and shell thickness were significantly higher due to dietary inclusion of Saccharomyces cerevisiae and Bioplus (Bageridizaj et al., 2006). The better results obtained for the eggshell quality parameters could be partly due to the fact that the probiotics and prebiotics influence on the metabolic activity of the beneficial bacteria colony within the layers' intestine, which positively influence mineral absorption rate, especially those of $\mathrm{Ca}^{2+}$ and $\mathrm{Mg}^{2+}$ (Roberfroid, 2000).The egg shell quality improvement is under the influence of the intestinal $\mathrm{Ca}^{2+}$ absorption rate improvement, phenomenon facilitated by the presence within feed of some fodder additives like prebiotics, as previously stated by other researches. This beneficial effect on eggshell quality due to probiotic feeding may be attributed to a favorable environment in the intestinal tract by feeding of $\mathrm{L}$. sporogenes, which might have helped to assimilate more calcium, which was evident by increased concentration of Ca in serum (Panda et al., 2008).

In the present study, diet additives did not significantly affect plasma levels of cholesterol, triglyceride and HDL. This finding was in agreement with Kurtoglu et al. (2004) who showed that probiotic did not affect serum cholesterol in 30-days period of experiment. But Mahdavi et al. (2005) report that probiotics could depress serum and egg yolk cholesterol concentrations. Cholesterol depressing effect of probiotics, prebiotics and/or synbiotic in the serum and egg yolk in layers requires further investigation. Adding Thepax or Biomin to diet significantly reduced blood levels of LDL compared to hens fed the other experimental diets. In addition, in some study, probiotic supplementation reduced the serum LDL cholesterol (Kalavathy et al., 2003). However, Hens fed the Thepax and Biomin diets did have decreased blood levels of LDL compared to hens fed the control diet. Baillon et al. (2004) reported that administration of probiotic increased neutrophils and monocytes in adult dogs. It has been recognized that the gut-associated immune system can be modulated by nutritional means (Koenen et al., 2004).

\section{CONCLUSION}

This study provides evidence that adding Yeasturer, A-Max, Thepax, Fermacto and Biomin to layer diets did not cause any beneficial effects on hens' performance with the exception of EW, so that the hens received Yeasturer and A-Max did show better EW than hens fed the control diet. In addition, dietary supplementation by Thepax or Biomin reduced blood levels of LDL. 
Am. J. Agri. \& Biol. Sci., 6 (2): 6 (2): 249-255, 2011

Table 7: Egg quality characteristics (egg index, yolk index, Haugh unit, egg shell weight and egg shell thickness) of hens fed experimental diets

\begin{tabular}{|c|c|c|c|c|c|}
\hline & \multicolumn{5}{|c|}{ Egg quality characteristics } \\
\hline & Egg index & Yolk index & Haugh unit Egg & shell weight & Shell thickness \\
\hline \multicolumn{6}{|l|}{ Treatments } \\
\hline Control & 75.17 & 44.37 & 70.80 & $6.56^{\mathrm{b}}$ & $39.00^{\mathrm{c}}$ \\
\hline Yeasture & 74.68 & 44.30 & 72.22 & $7.35^{\mathrm{a}}$ & $43.16^{\mathrm{ab}}$ \\
\hline A-Max & 73.82 & 44.19 & 71.59 & $7.40^{\mathrm{a}}$ & $43.66^{\mathrm{a}}$ \\
\hline Thepax & 78.79 & 44.47 & 71.03 & $7.23^{\mathrm{a}}$ & $42.33^{\mathrm{ab}}$ \\
\hline Fermacto & 74.11 & 44.35 & 73.31 & $7.13^{\mathrm{ab}}$ & $41.33^{\mathrm{b}}$ \\
\hline Biomin & 75.23 & 44.16 & 71.30 & $7.45^{\mathrm{a}}$ & $43.83^{\mathrm{a}}$ \\
\hline$P$ value & 0.174 & 0.999 & 0.073 & 0.039 & 0.0001 \\
\hline SEM & 1.395 & 0.525 & 1.243 & 0.199 & 0.648 \\
\hline
\end{tabular}

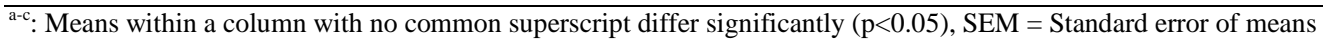

Table 8: White blood cell counts (heterophil, lymphocyte, monocyte, eosinophil and basophil) of hens fed experimental diets

\begin{tabular}{llllll}
\hline & Heterophile & Lymphocyte & Monocyte & Eosinophile & Basophile \\
\hline Treatments & & & & & \\
Control & 24.75 & 73.75 & 0.250 & 0.000 & 1.000 \\
Yeasture & 26.75 & 65.25 & 0.000 & 0.000 & 2.500 \\
A-Max & 29.25 & 66.00 & 0.750 & 0.750 & 3.250 \\
Thepax & 37.50 & 57.50 & 0.750 & 0.250 & 4.000 \\
Fermacto & 30.75 & 65.25 & 0.500 & 0.250 & 3.250 \\
Biomin & 34.50 & 61.25 & 0.000 & 0.500 & 4.000 \\
P value & 0.186 & 0.081 & 0.488 & 0.738 & 0.091 \\
SEM & 4.227 & 4.476 & 0.413 & 0.456 & 0.866 \\
\hline a-b : Means within a column with no common superscript differ significantly (p<0.05), SEM= Standard error of means &
\end{tabular}

Table 9: Blood lipids (Cholesterol, TG, HDL and LDL) of hens fed experimental diets

\begin{tabular}{lllll}
\hline & Cholesterol & TG & HDL & LDL \\
\hline Treatments & & & & \\
Control & 261.75 & 2448.75 & 80.50 & $79.25^{\mathrm{a}}$ \\
Yeasture & 205.00 & 2532.50 & 69.50 & $82.00^{\mathrm{a}}$ \\
A-Max & 332.75 & 3012.25 & 78.75 & $85.25^{\mathrm{a}}$ \\
Thepax & 474.25 & 1621.25 & 55.50 & $65.25^{\mathrm{b}}$ \\
Fermacto & 254.50 & 2822.50 & 67.50 & $84.50^{\mathrm{a}}$ \\
Biomin & 146.75 & 1643.75 & 59.00 & $64.00^{\mathrm{b}}$ \\
P value & 0.649 & 0.120 & 0.122 & 0.022 \\
SEM & 23.189 & 177.812 & 2.645 & 2.604 \\
\hline SEM Standard
\end{tabular}

SEM= Standard error of means

\section{ACKNOWLEDGEMENT}

Appreciation is expressed to Research Sector of Islamic Azad University, Aligodarz Branch, Iran, for financial support of this research.

\section{REFERENCES}

Aghaei, A.S.M., M. Chaji and M. Nazari, 2010. Effect of dried whey (probiotics ) and prebiotics in laying hens performance and intestinal Flora . J. Anim. Vet. Adv., 9: 1996-2000. DOI: 10.3923/javaa.2010.1996.2000

Bageridizaj, S., R. pirmohammadi and V. Bampidis, 2006. Effects of dietary probiotics on performance. Egg Quality and Yolk/Serum Cholesterol of Laying Hens. J. Anim. Vet. Adv., 5: 1175-1180. DOI: 10.3923/javaa.2006.1175.1180
Baillon, M.L., Z.V. Marshall-Jones and R.F. Butterwick, 2004. Effects of probiotic Lactobacillus acidophilus strain DSM13241 in healthy adult dogs. Am. J. Vet. Res., 65: 338-343. PMID: 15027683

Balevi, T., U.S. Ucan, B. Coskun, V. Kurtoglu and I.S. Cetingul, 2001. Effect of dietary probiotic on performance and humoral immune response in layer hens. Br. Poult. Sci. 42: 456-461. PMID: 11572620

Chen, Y.C., C. Nakthong and T.C. Chen, 2005. Improvement of laying hen performance by dietary prebiotic chicory oligofructose and inulin. Int. J. Poult. Sci., 2: 103-108. DOI: 10.3923/ijps.2005.103.108

Edens, W. 2003. An alternative for antibiotic use in poultry. Probiotics. Braz. J. Poultry Sci., 5: 75-97. DOI: 10.1590/S1516-635X2003000200001

Ehsani, M. and M. Torki, 2010. Effects of dietary inclusion of guar meal supplemented by $\beta$ mannanase on performance of laying hens, egg quality characteristics and diacritical counts of white blood cells. Am. J. Animal Vet. Sci., 5: 237243. DOI: 10.3844/ajavsp.2010.237.243

Gallazzi, D., A. Giardini, M.G. Mangiagalli, S. Marelli and V. Ferrazzi et al., 2008. Effects of Lactobacillus acidophilus D2/CSL on laying hen performance Ital. J. Anim. Sci., 7: 27-37. DOI: 10.4081/ijas.2008.27 
Ghasemi, R., M. Zarei and M. Torki, 2010. Adding medicinal herbs including garlic (Allium sativum) and thyme (Thymus vulgaris) to diet of laying hens and evaluating productive performance and egg quality characteristics. Am. J. Animal Vet. Sci., 5: 151-154. DOI: 10.3844/ajavsp.2010.151.154

Gibson, G.R. and R. Fuller, 2000. Aspects of in vitro and in vivo research approaches directed toward identifying probiotics and prebiotics for human use. J. Nutr. 130: 391S-395S. PMID: 10721913

Gibson, G.R. and B. Roberfroid, 1995. Dietary modulation of the human colonic microbiota. Introducing the concept of prebiotics. J. Nutr. 125: 1401-1412. PMID: 7782892

Kalavathy, R, N. Abdullah and S. Jalaludin, 2003. Effect of lactobacillus cultures on growth performance. Abdominal fat deposition, serum lipid and weight of organs of broiler chickens. Br. Poult. Sci., 44: 139-144. PMID: 12737236

Kalavathy, R., N. Abdullah, S. Jalaludin, M. Wong and Y.W. Ho, 2009. Effects of Lactobacillus cultures on performance of laying hens and total cholesterol. Lipid and fatty acid composition of egg yolk. J. Sci. Food Agric., 89: 482-486. (www.interscience.wiley.com). DOI: 10.1002/jsfa.3477

Koenen, M.E., J. Karmer, R.V.D. Hulst, L. Heres and S.H. Jeurissen et al., 2004. Immunomodulation by probiotic lactobacilli in layer and meat-type chickens. Br. Poult. Sci., 45: 355-366. DOI: 10.1080/00071660410001730851

Kurtoglu, V., F. Kurtoglu, E. Seker, B. Coskun and T. Balevi et al., 2004. Effect of probiotic supplementation on laying hen diets on yield performance and serum egg yolk cholesterol. Food Additives Contaminants, 21: 817-823. DOI: 10.1080/02652030310001639530

La Ragione, R.M., G. Casula, S.M. Cutting and M.J. Woodward, 2001. Bacillus subtilis spores competitively exclude Escherichia coli O78:K80 in poultry. Vet. Microbiol., 79: 133-142. DOI:10.1016/S0378-1135(00)00350-3

Li, L., C.L. Xu, C. Ji, Q. Ma and K. Hao et al., 2006. Effect of a dried Bacillus subtilis culture on egg quality. Poult. Sci., 85: 364-368. DOI: 10.4081/ijas.2008.27.

Mahdavi, A.H., H.R. Rahmani and J. Pourreza, 2005. Effect of probiotic supplements on egg quality and laying hen's performance. Int. J. Poult. Sci., 4: 488-492. DOI: 10.3923/ijps.2005.488.492
Mutus, R., N. Kocabagli, M. Alp, N. Acar and M. Eren et al., 2006. The effect of dietary probiotic supplementation on tibial bone characteristics and strength in broilers. Poult. Sci. 85: 1621-1625. PMID: 16977848

Panda, A.K, S.S.R. Rao, V. R. Manteta and S.S Sharma, 2008. Effect of probiotic (Lactobacillus sporogenes) feeding on egg production and quality. yolk cholesterol and humoral immune response of White Leghorn layer breeders. J. Sci. Food. Agric. 88: 43-47. DOI: 10.1002/jsfa.2921

Panda, A.K., M.R. Reddy, R.A. Rama, N. K. Praharah, 2003. Production performance, serum/yolk cholesterol and immune competence of white leghorn layers as influenced by dietary supplementation with probiotic. Trop. Anim. Health. Prod., 35: 85-94. DOI: 10.1023/A:1022036023325

Pelicano, E.R.L. P.A .Souza, H.B.A.Souza, F.R. Leonel and N.M.B.L. Zeola et al., 2004. Productive traits of broiler chickens fed diets containing different growth promoters. Braz. J. Poult. Sci., 6: 177-182. doi: 10.1590/S1516-635X2004000300008

Roberfroid, M.B. 2000. Prebiotics and probiotics. Are they functional foods. Am. J. Clin. Nutr., 71: 162S168S. PMID: 10837317

Roberfroid, M.B., 2001. Prebiotics: Preferential substrates for specific germs. Am. J. Clin. Nut., 73: 406S-409S. PMID: 11157349

Saffar, A. and F. Khajali, 2010. Application of Meal Feeding and Skip-A-Day Feeding With or Without Probiotics for Broiler Chickens Grown at HighAltitude to Prevent Ascites Mortality. Am. J. Animal Vet. Sci., 5: 13-19. DOI: 10.3844/ajavsp.2010.13.19

Shim, S.B., I.H. Williams and M.W.A. Verstegen, 2005. Effects of dietary fructo-oligosaccharides on growth, villous height and disaccharidase activity of the small intestine, $\mathrm{pH}, \mathrm{VFA}$ and ammonia concentration in the large intestine of weaned pigs. Acta. Agric. Scand. Section A-Anim. Sci., 55: 9197. DOI: $10.1080 / 09064700500307201$

Sims, M.D., K.A. Dawson, K.E. Newman, P. Spring and D.M. Hooge.et al., 2004. Effects of dietary mannan oligosaccharide, bacitracin methylene disalicylate. Or both on the live performance and intestinal microbiology of turkeys. Poult. Sci., 83: 1148-1154. PMID: 15285506

Timmerman H.M., C.J Koning L. Muler, F.M Rombouts and A.C. Beynen, et al., 2004. Monostrain, multistrain and multispecies probiotics-a comparison of functionality and efficacy. Int. J. Food Microbiol., 96: 219-33. PMID: 15454313 
Xu, Z. R., C.H. Hu, M.S. Xia, X.A. Zhan and M.Q. Wang et al., 2003. Effects of dietary frutooligosaccharide on digestive enzyme activities, intestinal microflora and morphology of malebroilers. Poult. Sci., 82: 1030-1036. PMID:12817461
Yoruk, M.A. M.Gul, A. Hayirli and M. Macit, 2004. The effects of supplementation of humate and probiotic on egg production and quality parameters during the late laying period in hens. Poult. Sci., 83: 84-88. PMID: 14761088 